\title{
INTERDISCIPLINARIDADE E FORMAÇÃO NA ÁREA DE FARMÁCIA
}

\author{
INTERDISCIPLINARITY AND TRAINING IN THE PHARMACY AREA
}

INTERDISCIPLINARIDAD Y FORMACIÓN EN EL ÁREA DE FARMACIA

\author{
Iane Franceschet de Sousa ${ }^{1}$ \\ Paulo Roberto Haidamus de Oliveira Bastos ${ }^{2}$
}

Resumo A interdisciplinaridade apresenta-se como um desafio e uma necessidade do setor saúde, tendo em vista o redirecionamento do modelo assistencial. Este estudo objetivou desvelar a compreensão de coordenadores de cursos de graduação em Farmácia da região Centro-Oeste do Brasil sobre a interdisciplinaridade na formação do farmacêutico. Utilizou-se a abordagem qualitativa, no pressuposto metodológico da fenomenologia, segundo a modalidade do fenômeno situado. Foram coletados 16 depoimentos entre junho de 2011 e abril de 2012 e submetidos à descrição, redução e interpretação fenomenológica. A construção dos resultados foi realizada com base nas análises ideográfica e nomotética dos depoimentos, dos quais emergiram 12 temas, agrupados em três categorias principais: interdisciplinaridade no currículo, interdisciplinaridade na formação do farmacêutico e interdisciplinaridade na atuação do farmacêutico no sistema de saúde. Alguns resultados revelados referem-se à necessidade de compreender melhor como a interdisciplinaridade dialoga com o currículo de Farmácia e à superação de obstáculos técnicos e políticos que impedem a prática interdisciplinar efetiva na formação dos farmacêuticos, entre eles a falta de capacitação docente e as disputas de poder entre áreas.

Palavras-chave educação em farmácia; currículo; interdisciplinaridade; diretrizes curriculares nacionais.
Abstract Interdisciplinarity is presented as a challenge and a need of the health sector, with a view to redirect the health care model. This study aimed to unveil the understanding the coordinators of undergraduate programs in Pharmacy in Midwestern Brazil have of interdisciplinarity in training pharmacists. A qualitative approach was used in the methodological fundamentals of the phenomenology, pursuant to the mode of the phenomenon. A total of 16 testimonials were collected between June 2011 and April 2012, which were then submitted to description, reduction, and phenomenological interpretation in order to reach knowledge on the phenomenon studied. Results were built based on ideographic and nomothetic analyses of the testimonials, from which 12 topics grouped into three main categories emerged: curriculum interdisciplinary, interdisciplinary in training the pharmacists, and interdisciplinarity in the pharmacist's role in the health system. Some of the results that were obtained point to the need to better understand how interdisciplinary converses with the Pharmacy curriculum and overcoming technical and political obstacles that prevent the practice of effective interdisciplinary in the training of pharmacists, including the lack of training for faculty and competition for power among areas.

Keywords Education in pharmacy; curriculum; interdisciplinarity; national curriculum guidelines. 


\section{Introdução}

O cenário ainda dominante na formação dos farmacêuticos reflete o perfil flexneriano de ensino, que, de acordo com Pagliosa e Da Ros (2008), enfatiza o modelo biomédico, centrado na doença e no hospital, conduzindo os alunos a uma visão reducionista. A visão especialista e biologicista, a ênfase nas especialidades e a divisão entre ciclo básico e profissionalizante, também são características ainda observadas nos currículos dos cursos de Farmácia, mesmo após a implementação das Diretrizes Curriculares Nacionais (DCN), de 2002 (Brasil, 2002). São incipientes as iniciativas que visam alterar o modelo de formação dos farmacêuticos, valorizando a atuação em equipe de saúde, a prática interdisciplinar, o currículo integrado e o foco na atenção básica.

As críticas recorrentes a esse modelo de formação começaram a acontecer com maior intensidade na década de 1960 em todo o mundo, evidenciando o descompromisso com a realidade e as necessidades da população (Pagliosa e Da Ros, 2008).

No mesmo período, a ênfase na atuação interdisciplinar foi retomada em diversos campos científicos. O movimento em prol da interdisciplinaridade surgiu na Europa, principalmente na França e na Itália, em meados da década de 1960, época em que explodiram os movimentos estudantis, reivindicando um novo estatuto de universidade e de escola. Este movimento nasceu como oposição a todo conhecimento que privilegiava o capitalismo epistemológico de certas ciências, como oposição à alienação da academia às questões cotidianas e às organizações curriculares que evidenciavam a excessiva especialização (Fazenda, 2009).

No Brasil, o eco das discussões internacionais sobre interdisciplinaridade chega no final da década de 1960 com sérias distorções. Os estudos precursores sobre interdisciplinaridade foram conduzidos por Japiassu, Fazenda e Jantsch, a partir da década de 1970, quando a preocupação maior era traduzir o termo e compreender o seu significado (Fazenda, 2009).

De acordo com Fazenda (2009), é impossível a construção de uma única, absoluta e geral teoria da interdisciplinaridade. A interdisciplinaridade compreende uma nova forma de pensar e fazer o ato de ensinar e aprender, pois por meio de uma postura interdisciplinar temos a oportunidade de ser aprendizes e produtores dos mais diversos saberes. O termo interdisciplinaridade implica relação de reciprocidade, de mutualidade, de substituição da concepção fragmentária por uma concepção unitária do ser humano, ou seja, um movimento de renovação frente aos problemas do ensino e da pesquisa (Gattás e Furegato, 2006).

A interdisciplinaridade não é ciência, nem ciência das ciências, mas é o ponto de encontro entre o movimento de renovação da atitude frente aos 
problemas de ensino e pesquisa e a aceleração do conhecimento científico. Também não é uma panaceia que garantirá um ensino adequado, ou um saber unificado, mas um ponto de vista que permite uma reflexão aprofundada, crítica e salutar. Podemos dizer que é a possibilidade de eliminação do hiato existente entre a atividade profissional e a formação escolar (Fazenda, 1993).

A interdisciplinaridade não significa negar as especialidades e especificidades de cada profissão, mas sim respeitar o território de cada campo de conhecimento, bem como distinguir os pontos que os unem e os diferenciam. Cada especialidade precisa ultrapassar sua área de formação e competência, evidenciando seus próprios limites e buscando a contribuição de outras disciplinas. Deste modo, a interdisciplinaridade busca a superação da racionalidade científica positivista, aparece como entendimento de uma nova forma de institucionalizar a produção do conhecimento nos espaços da pesquisa, na articulação de novos paradigmas curriculares e na comunicação do processo de perceber as várias disciplinas (Saupe e Budó, 2006).

A razão do direcionamento para a interdisciplinaridade é o caminho natural na área da saúde da sociedade contemporânea, a qual está em constante mudança devido à globalização, expansão dos sistemas de comunicação e informação, e diversidade cultural dos fornecedores e dos usuários de serviços da saúde. Além disso, a efetividade do sistema de saúde envolve múltiplas disciplinas que devem se comunicar para oferecer serviços de qualidade (Gray, 2005).

A exigência interdisciplinar impõe às especialidades que transcendam suas próprias áreas, tomando consciência de seus limites e acolhendo as contribuições das outras disciplinas. A busca é de um conhecimento mais amplo, não-fragmentado, tendo como desafio o diálogo e a interação das disciplinas, para além das ações multidisciplinares, que produzem conhecimentos justapostos para um mesmo problema (Garcia et al., 2007; Gattás e Furegato, 2006).

A discussão que envolve a reforma no ensino dos profissionais da saúde, inclusive dos farmacêuticos, está vinculada a três eixos: ao modelo assistencial a partir da implementação do Sistema Único de Saúde (SUS), ao modelo técnico-científico e ao modelo pedagógico. Qualquer processo de mudança que se restringe a um desses níveis não trará, efetivamente, alterações que gerem impacto na atuação prática do profissional. A formação de um profissional competente e compromissado socialmente não está garantida por alterações de grade curricular, implementação de modelos pedagógicos sem fundamentação no processo de construção do conhecimento, alocação de novas disciplinas, introdução de técnicas e instrumentos didáticos (Garcia et al., 2007).

Desta forma, destaca-se a importância em discutir as bases da interdisciplinaridade na formação dos farmacêuticos, para buscar uma atuação que 
vise à integralidade das ações direcionadas ao cumprimento dos preceitos do SUS.

\section{Diretrizes Curriculares Nacionais como norteadora da formação farmacêutica}

Retomando o ensino farmacêutico no Brasil, previamente às diretrizes de 2002, são 170 anos (1832-2002) de alterações e reformas curriculares que demonstram claramente uma crise na profissão. Com o passar do tempo, o farmacêutico foi alienado da sua função na farmácia, migrando para outras áreas como análises clínicas e alimentos, em busca de maior valorização profissional e maiores salários (Soares et al., 2008; Silva, 2009).

O currículo mínimo de 1962 e, depois, o de 1969 foram caracterizados por uma formação engessada, de caráter tecnicista, biologicista, valorizando cada vez mais as especializações (Soares et al., 2008; Silva, 2009; Cecy, 2011). Convém lembrar que os objetivos dos currículos mínimos eram: ser facilmente transferido de uma instituição de ensino para outra; e garantir qualidade e uniformidade mínimas aos cursos que conduziam a um diploma profissional (Brasil, 1997).

Além disso, os currículos mínimos vinham marcados de rigidez excessiva e diminuição da liberdade e autonomia das instituições para organizarem suas atividades de ensino, resultando em ineficácia, desestímulo à inovação e falta de diversificação da formação oferecida (Brasil, 1997).

A partir da Lei de Diretrizes e Bases da Educação, as instituições de ensino ganharam respaldo político para agir de forma autônoma na criação e alteração dos currículos dos seus cursos, desde que respeitadas as diretrizes pertinentes a cada curso (Brasil, 1996). Isto serviu de base para a criação das diretrizes curriculares para os cursos do ensino superior, no caso da Farmácia, através da resolução CNE/CES n. 2, de 19 de fevereiro de 2002 (Brasil, 2002).

É importante destacar que as DCN foram elaboradas a partir do parecer n. 1300, de 2001, do Conselho Nacional de Educação, o qual foi fundamental para a consolidação das DCN para o curso de Farmácia. Consta, neste parecer, o objeto das diretrizes:

Permitir que os currículos propostos possam construir perfil acadêmico e profissional com competências, habilidades e conteúdos, dentro de perspectivas e abordagens contemporâneas de formação pertinentes e compatíveis com referências nacionais e internacionais, capazes de atuar com qualidade, eficiência e resolutividade, no Sistema Único de Saúde (SUS), considerando o processo da Reforma Sanitária Brasileira (Brasil, 2001a, p. 4). 
Ainda o mesmo parecer n. 1300/2001 estabelece o objetivo das DCN para os cursos de Farmácia:

Levar os alunos dos cursos de graduação em saúde a aprender a aprender, que engloba aprender a ser, aprender a fazer, aprender a viver juntos e aprender a conhecer, garantindo a capacitação de profissionais com autonomia e discernimento para assegurar a integralidade da atenção e a qualidade e humanização do atendimento prestado aos indivíduos, famílias e comunidades (Brasil, 2001a, p. 4).

A Organização das Nações Unidas para a Educação, Ciência e Cultura (Unesco) aborda tais características como os 'quatro pilares da educação, conforme publicado em 1996, no relatório da Comissão Internacional sobre Educação para o Século XXI. Estas são competências citadas em vários momentos das DCN, enfatizando que seguem as recomendações internacionais (Delors, 1996; Brasil, 2002).

Portanto, as DCN nada mais são do que recomendações ou orientações destinadas às instituições de ensino e às coordenadorias de cursos para a elaboração dos currículos, já que há autonomia para tal. Conforme relatam os pareceres n. 1.300/2001 e 1.133/2001, do Conselho Nacional de Educação, dentro da perspectiva de assegurar a flexibilidade, a diversidade e a qualidade da formação oferecida aos estudantes, as diretrizes devem estimular a superação das concepções antigas e herméticas das grades curriculares, muitas vezes meros instrumentos de transmissão de conhecimento e informações e garantir uma sólida formação básica, preparando o futuro graduado para enfrentar os desafios das rápidas transformações da sociedade, do mercado de trabalho e das condições de exercício profissional (Brasil, 2001a; Brasil, 2001b).

Nas DCN para os cursos de graduação em Farmácia, a saúde é considerada uma área interdisciplinar, pois seu objeto - 'o processo saúde-doença humano' - envolve as relações sociais, a biologia e as expressões emocionais (Brasil, 2002; Garcia, et al., 2007).

As DCN dos cursos de graduação em Farmácia apontam a necessidade da formação de profissionais capazes de garantir assistência integral à saúde (Brasil, 2002). No entanto, é preciso avançar mais neste sentido. A maioria dos profissionais continua sendo formada por meio de currículos fragmentados em disciplinas e áreas de concentração básica e clínica, sem muita inter-relação entre os conteúdos. Além disso, as dificuldades na interpretação e implementação das DCN pelas instituições de ensino superior geraram o surgimento de matrizes disciplinares heterogêneas, que muitas vezes sofrem sucessivos processos de reorganização. Diversos cursos de Farmácia ainda possuem as atividades de estágio condensadas no último semestre de 
formação, gerando descompasso cronológico entre o conteúdo teórico estudado e sua aplicação prática.

De acordo com Araújo e Prado (2008), o ponto fundamental da reforma curricular do ensino farmacêutico prende-se à mudança de mentalidade, trazendo também para o currículo uma visão humanista, uma vez que o currículo anterior era basicamente tecnicista, que consagrava a ideia de que o farmacêutico é o profissional do fazer, aquele ligado à tecnologia de ponta, que está sempre aprendendo a lidar com equipamentos novos nas indústrias farmacêuticas. Mas o farmacêutico também deve conciliar a noção do processo de fabricação e de controle dos medicamentos e os subsídios para orientar a população sobre a utilização correta desses fármacos.

Apesar dos avanços teoricamente obtidos com as DCN, aproximando o farmacêutico do sistema de saúde, dando um sentido mais amplo e flexível a sua formação, ainda não sabemos o impacto dessas mudanças, na prática. O que se pode afirmar, devido a alguns estudos já realizados (Soares et al., 2008; Leite et al., 2006; Furtado, 2008), é que há diferenças consideráveis na forma de interpretação e de implementação das DCN pelas instituições de ensino.

A interdisciplinaridade, apesar de ser um tema já discutido há algum tempo, está presente nas DCN, que destacam a conduta interdisciplinar como uma das habilidades específicas que deve estar garantida na formação do farmacêutico (Brasil, 2002). Todavia, não se conhece como estão sendo implementadas as atividades interdisciplinares nos currículos dos cursos de Farmácia, após as DCN, tampouco a forma como a prática interdisciplinar está sendo interpretada pelos gestores dos cursos, na figura dos coordenadores e diretores das faculdades de Farmácia, bem como das equipes docentes.

Desta forma, o estudo aqui tratado objetivou desvelar qual a compreensão dos coordenadores de cursos de Farmácia da região Centro-Oeste do Brasil, sobre a relação entre a interdisciplinaridade e a formação dos farmacêuticos a partir da implementação das DCN, com vistas à atuação desses profissionais no SUS.

\section{Percurso metodológico}

Para o desenvolvimento do estudo optou-se pela metodologia qualitativa, mais especificamente, a Fenomenologia, que permite construir o conhecimento a partir da experiência vivida do sujeito que, no dia a dia, vivencia o fenômeno em suspensão. Além disso, a falta de registros e estudos sobre a formação farmacêutica, sobretudo após a implantação das DCN, parece ser insuficiente para o desenvolvimento de um estudo exploratório.

A Fenomenologia surgiu no campo da Filosofia e pretendeu ser um método que possibilita chegar à essência do próprio conhecimento (Forghieri, 
1993). A Fenomenologia ensina como chegar à essência de um determinado fenômeno, como conseguir a vivência da realidade, através da descrição do fenômeno que a experiência nos oferece (Ribeiro Júnior, 1991).

Dentro da Fenomenologia, a opção pela modalidade do fenômeno situado a partir das concepções de Martins e Bicudo (1994) foi a mais apropriada para o alcance dos objetivos propostos por esta pesquisa. Esta modalidade aborda três fases de pesquisa: a descrição, a redução e a interpretação fenomenológica.

No método do fenômeno situado, o sujeito fica livre para expressar a sua experiência vivida, sua experiência consciente, livre de pressupostos e preconceitos, sem amarras e teorias de explicação causal sobre os fatos. Neste método, não há hipóteses definidas a priori (Martins, 1992).

A interdisciplinaridade, compreendida como atitudes e experiências vividas, englobando as dimensões pessoais, não apresenta características possíveis de serem estudadas quantitativamente. Desta forma, a escolha do método do fenômeno situado vem ao encontro dos objetivos e necessidades da pesquisa, a fim de manter rigor metodológico, mesmo que não o da precisão numérica.

O estudo foi realizado com 16 coordenadores de cursos de Farmácia da região Centro-Oeste, entre junho de 2011 e abril de 2012. Na pesquisa fenomenológica, o número de participantes entrevistados se estabelece a partir das convergências e repetições dos discursos coletados. Verificou-se que a coleta dos depoimentos com os coordenadores de curso demonstrou convergências e repetições no discurso em todos os quesitos avaliados.

A obtenção das descrições foi realizada por meio de entrevistas gravadas, tendo como questão norteadora: “Como você compreende (o que significa para você) a interdisciplinaridade: no currículo, na formação do farmacêutico e na atuação do farmacêutico para o SUS?"

Os depoimentos foram transcritos e numerados de um a 16 e, após sucessivas leituras, foram separadas as unidades de significado, por meio da redução fenomenológica. Esta etapa é chamada de epoché, que consiste na análise da fala dos sujeitos e na coleta da essencialidade do discurso, o que permite compreender o fenômeno estudado. A partir disso, as unidades de significado de cada discurso foram transportadas para o quadro da análise ideográfica, o qual foi elaborado a partir do modelo proposto por Sadala (1995).

A terceira etapa do percurso metodológico consistiu na interpretação fenomenológica, que aponta as convergências e divergências observadas no discurso reduzido dos sujeitos, dispostas em categorias estruturais, ou seja, a busca dos consensos e dissensos das falas coletadas. Esta etapa é construída a partir de uma matriz, com os pontos convergentes e divergentes expressos em cada unidade de significado. A etapa é chamada de análise nomotética, que resulta nas ideias centrais do tema pesquisado. De acordo com Sadala e Marques (2006), ela desvela os invariantes do fenômeno estudado, sua 
essência. Segundo os autores, neste caminhar da análise ideográfica para a análise nomotética, ao tematizar e categorizar as convergências, pode-se alcançar as verdades gerais sobre o fenômeno estudado, na perspectiva daqueles que o vivenciam.

O Quadro 1 apresenta os 12 temas identificados a partir da metodologia executada.

\section{Quadro 1}

\begin{tabular}{|c|c|}
\hline Categorias & Temas propostos \\
\hline $\begin{array}{l}1 \text { - Interdisciplinaridade no } \\
\text { currículo }\end{array}$ & $\begin{array}{l}\text { A - O que se entende por interdisciplinaridade no currículo } \\
\text { B - Estágios, pesquisa e extensão } \\
\text { C - Construção da estrutura curricular generalista } \\
\text { D - Formação docente }\end{array}$ \\
\hline $\begin{array}{l}2 \text { - Interdisciplinaridade na } \\
\text { formação }\end{array}$ & $\begin{array}{l}\text { E - Inserção do acadêmico no SUS desde a graduação } \\
\text { F - Formação integral e humanista do acadêmico } \\
\text { G - Contrastes entre a formação generalista e a formação especialista } \\
\text { H - Perfil do acadêmico } \\
\text { I - Pós-graduação }\end{array}$ \\
\hline $\begin{array}{l}\text { 3- Interdisciplinaridade na atuação } \\
\text { do farmacêutico no SUS }\end{array}$ & $\begin{array}{l}\text { J - Fortalecimento da categoria farmacêutica } \\
\text { K - Trabalho em equipe multiprofissional } \\
\text { L - Sistema público e sistema privado }\end{array}$ \\
\hline
\end{tabular}

Fonte: Os autores.

SUS: Sistema Único de Saúde

A pesquisa aqui descrita foi aprovada pelo Comitê de Ética em Pesquisa com Seres Humanos da Universidade Federal de Mato Grosso do Sul (UFMS), sob o protocolo n. 1.886, de 25 de novembro de 2010.

\section{Resultados e discussão}

Para a interpretação das categorias expostas no Quadro 1, foram analisadas as convergências e divergências das falas coletadas e identificadas em cada tema. A seguir, os principais resultados. 
No que concerne à categoria 1 , destacam-se duas respostas ao tema A: “A interdisciplinaridade é a relação entre disciplinas e conteúdos, onde uma disciplina complementa a outra para que o acadêmico tenha a compreensão de todo o contexto de disciplinas ministradas durante o curso" e "A interdisciplinaridade consiste na junção de áreas, para que o acadêmico possa ter uma visão global do curso".

$\mathrm{O}$ exposto pelos entrevistados demonstra que o que se entende por interdisciplinaridade no currículo, na verdade, consiste na pluridisciplinaridade, onde há uma justaposição de disciplinas assemelhadas e domínios de conhecimento, formando áreas com conteúdos afins, com menor fragmentação. As relações entre as disciplinas e áreas ocorrem num só nível e com múltiplos objetivos, indicando a existência de alguma cooperação (Tribarry, 2003; Garcia et al., 2007; Saupe, Cutolo e Wendhausen, 2005).

No entanto, a interdisciplinaridade exige mais, existindo uma axiomática comum a um grupo de disciplinas conexas e definidas em um nível hierárquico imediatamente superior, o que introduz a noção de finalidade. É um tipo de sistema de dois níveis e de objetivos múltiplos com a coordenação procedendo de nível superior. Este nível superior coordena um campo disciplinar, como é o exemplo do campo da saúde mental (Almeida-Filho, 2005; Tribarry, 2003).

Quanto ao tema B, que trata de estágios, pesquisa e extensão, evidenciou-se três respostas: "Os estágios possibilitam a vivência interdisciplinar"; "A interdisciplinaridade não ocorre nos estágios porque os acadêmicos e os professores não estão preparados para esta vivência" e "A interdisciplinaridade não ocorre na pesquisa e na extensão, porque essas áreas não se entendem totalmente, cada uma tem suas prioridades, então fica difícil fazer interdisciplinaridade".

De acordo com Fazenda (1993), a interdisciplinaridade relaciona-se com atitudes, com a prática (por isso é preciso vivenciar o processo), com um olhar diferenciado para o cotidiano, como trabalho conjunto na busca de soluções. A interdisciplinaridade não se ensina nem se aprende, apenas vive-se.

Como os estágios são um meio de os acadêmicos vivenciarem a prática profissional, entende-se que este é um momento essencial para que a interdisciplinaridade seja experimentada. Mas, para tanto, precisa ser estimulada, tanto pelos docentes quanto pelos preceptores do local de estágio.

A pesquisa e extensão, completando o tripé acadêmico junto ao ensino, são fundamentais e indissociáveis para propiciar ao acadêmico uma vivência universitária completa e prepará-lo para atuar na sociedade.

O conceito de extensão universitária, assim definido na Política Nacional de Extensão Universitária (Brasil, 2012), demonstra que a extensão universitária, sob o princípio constitucional da indissociabilidade entre ensino, pesquisa e extensão, é um processo essencialmente interdisciplinar, educativo, 
cultural, científico e político que promove a interação transformadora entre universidade e outros setores da sociedade.

A extensão é uma via de mão-dupla, com trânsito assegurado à comunidade acadêmica, que encontrará, na sociedade, a oportunidade de elaboração da práxis de um conhecimento acadêmico. No retorno à universidade, docentes e discentes trarão um aprendizado que, submetido à reflexão teórica, será acrescido àquele conhecimento. Portanto, a extensão é uma excelente oportunidade para incutir as práticas interdisciplinares na vivência dos acadêmicos.

Quanto ao tema C, no que respeita à construção da estrutura curricular generalista, destacam-se sete respostas: "A quebra de pré-requisitos facilitou a compreensão do todo por parte dos acadêmicos"; "É possível trabalhar melhor a interdisciplinaridade através de um currículo integrado, do sistema modular e de metodologias ativas de ensino-aprendizagem"; "O currículo generalista está "em construção", pois não sabemos montar um currículo interdisciplinar"; "O modelo atual de ensino em Farmácia é tradicional, de ministrar conteúdos"; "Ser generalista já contempla a interdisciplinaridade"; "O aumento da carga-horária curricular poderia melhorar a formação interdisciplinar em todas as áreas requeridas pelas DCN, mas é contraproducente" e "O currículo de Farmácia é extremamente amplo, retaliado, com brigas entre áreas de conhecimento".

A construção do currículo generalista foi um ponto muito evidenciado nos depoimentos, demonstrando preocupação com a formação deste perfil profissional e apontando problemas técnicos e políticos que impedem a implementação de um currículo generalista interdisciplinar.

Dos quase 500 cursos de graduação em Farmácia em funcionamento no Brasil (Brasil, 2010), há poucos relatos publicados de iniciativas de mudanças no sistema de ensino, o qual continua centrado no modelo tradicional de transmissão de conteúdos, sem utilizar métodos integrados e ativos de ensino-aprendizagem.

Uma dessas iniciativas foi publicada por Carpes e Magni (2009), descrevendo o processo de mudança curricular no curso de graduação em Farmácia do Centro Universitário Franciscano. Outro artigo publicado descreve a experiência da utilização do método da problematização em cenários de prática, como nos estágios do curso de graduação em Farmácia da Faculdade de Ciências Médicas e da Saúde de Juiz de Fora (Silva, Miguel e Teixeira, 2011).

No entanto, conforme enfatiza Garcia e colaboradores (2007), mudanças restritas a apenas alguns pontos do processo de formação não garantem alterações que gerem impacto na atuação prática do profissional.

Araújo (2006) critica o modelo de formação dos profissionais de saúde, salientando que a relação da academia com a sociedade deve ser reorientada. Critica o modelo bancário de educação, citando Paulo Freire, em que mera- 
mente se transmite o conhecimento, esperando que os alunos façam as correlações necessárias entre o referencial teórico e a práxis, entre a academia e a sociedade.

Em relação ao tema D, sobre formação docente, destaca-se a seguinte resposta: “Os professores foram formados no modelo tradicional, especializado, não sabem trabalhar a interdisciplinaridade".

Braid, Machado e Aranha (2012) realizaram um estudo exploratório dos artigos publicados sobre a inovação curricular na área da saúde, entre 2005 e 2011. Os autores enfatizam o incipiente volume de artigos publicados sobre a formação docente, já que as diretrizes propõem uma inovação curricular que inverte toda a lógica no processo de ensino e aprendizagem e o docente é um ator fundamental no processo de construção, implantação e implementação de inovações curriculares.

Soares e colaboradores (2008) indicam como um dos problemas na formação dos profissionais farmacêuticos a inadequada formação pedagógica dos professores, tanto na graduação quanto na pós-graduação. Além disso, a existência relativamente nova do SUS traz como consequência a falta de recursos humanos identificados com o novo paradigma de saúde, os princípios regentes do SUS e até mesmo dotados de experiência sobre a nova realidade sanitária brasileira.

De acordo com Fazenda (2009), para ensinar a interdisciplinaridade, o professor precisa ser o mestre, aquele que sabe aprender com os mais novos. O professor precisa ser o condutor do processo de ensino-aprendizagem, precisa saber ver no aluno aquilo que nem o próprio aluno havia lido nele mesmo.

De acordo com Rossoni e Lampert (2004), é um desafio para o professor romper com os limites da sua própria formação fragmentada e construir relações com outras áreas do conhecimento, inclusive oportunizando aos alunos cenários diversificados de prática na realidade local.

Quanto à categoria 2, sobre interdisciplinaridade na formação, cinco temas foram encontrados. O tema $\mathrm{E}$ se refere à inserção do acadêmico no SUS desde a graduação, no qual três respostas estão destacadas: "Inserir o acadêmico no SUS é difícil, mais difícil nas instituições privadas do que nas públicas, é um problema, apesar de ser imprescindível para cumprir as DCN"; "No SUS, o acadêmico consegue fazer a interdisciplinaridade, implementar o que foi aprendido nas disciplinas, trabalhar na comunidade" e "A interdisciplinaridade pode ser aplicada no SUS, mas o acadêmico fica muito distante dessa realidade".

As DCN, no parágrafo único do artigo $5^{\circ}$, que estabelece as competências específicas para a formação do farmacêutico, determinam que a formação do farmacêutico deve contemplar as necessidades sociais da saúde, a atenção integral da saúde no sistema regionalizado e hierarquizado de referência e contrarreferência e o trabalho em equipe, com ênfase no SUS (Brasil, 2002). 
O aprendizado no SUS deve envolver tanto o conhecimento técnico, a aquisição de habilidades e de atitudes frente às necessidades do sistema de saúde e a atuação do farmacêutico. Deficiências na formação do farmacêutico para o SUS podem estar relacionadas com a falta de oportunidades em vivenciar o SUS, através das atividades práticas, como os estágios e as atividades de extensão.

$\mathrm{O}$ tema $\mathrm{F}$ trata da formação integral e humanista do acadêmico e desvelou a seguinte resposta: "A interdisciplinaridade está relacionada com questões humanistas, com a formação integral em saúde, com a saúde coletiva, com a formação do acadêmico como ser humano e não só como profissional".

As DCN estimulam a formação de farmacêuticos com visão mais humanista, crítica e reflexiva, para atuar em todos os níveis de atenção à saúde (Brasil, 2002). Esse perfil de formação tem relação direta com a prática interdisciplinar, a qual possibilita o crescimento pessoal com o crescimento da equipe de saúde.

Quanto ao tema G, sobre os contrastes entre a formação generalista e a formação especialista, destacam-se quatro respostas: “O farmacêutico generalista não sai bem formado em todas as áreas de atuação, comprometendo a qualidade da sua formação, pois não serão bons especialistas"; “O farmacêutico especialista deixa de lado a interdisciplinaridade"; "Com as DCN e a formação generalista criou-se o desafio de desenvolver a formação do farmacêutico, vai melhorar a formação" e "As DCN pioraram muito a formação do farmacêutico".

Os depoimentos demonstram que há divergências entre considerar a formação generalista como algo positivo ou algo negativo na profissão. A categoria farmacêutica já vem discutindo, no decorrer da última década, a dificuldade de formar um farmacêutico generalista com o compromisso de manter a competência em todas as áreas que compreendem o âmbito profissional (análises clínicas, tecnologia de alimentos e fármaco-medicamentos) (Soares et al., 2008).

Além disso, de acordo com a Federação Internacional dos Farmacêuticos (FIP), é cada vez mais aceito que a formação inicial de graduação em Farmácia não pode fornecer profissionais de saúde completos, com tudo o que eles precisam saber. Os estudantes devem estar preparados para a aprendizagem ao longo da vida com maior ênfase no 'saber fazer', ou seja, na aquisição de habilidades (Anderson et al., 2008).

Araújo (2006) enfatiza que o conhecimento gerado no século XX foi substituído pelo ensino fragmentado e visual, e que a interdisciplinaridade se coloca como uma possibilidade de se corrigir distorções provocadas pelo excesso das especializações e sua consequência - a fragmentação do conhecimento. Na visão do autor, a interdisciplinaridade vem contribuir para diminuir as arestas deixadas por uma formação extremamente especializada. 
Desta forma, pode-se afirmar que a interdisciplinaridade auxilia na formação generalista, mas não exclui as especialidades. Há o falso engano, segundo Soares e colaboradores (2008), de que o termo generalista pressupõe pessoas com uma visão geral em contraposição ao especialista que detém conhecimentos específicos. O significado encaminha a interpretação de que o limite da formação está onde começa os conhecimentos específicos.

Quanto ao tema $\mathrm{H}$, que versa sobre o perfil do acadêmico, duas respostas foram reveladas nas entrevistas: "Os acadêmicos vêm do ensino médio com deficiências de aprendizado" e "A busca pela interdisciplinaridade é pessoal, depende do próprio acadêmico em buscar esse crescimento".

Soares e colaboradores (2008) salientam que muitos estudantes vêm de um ensino básico deficitário, tendo que definir a orientação profissional precocemente, prestes a graduar-se numa 'profissão' que mal conhece. Esse mesmo acadêmico não recebe uma formação para a ciência, filosofia e cultura adequadas para sua constituição como cidadão de nível educacional superior. Esta lacuna reflete diretamente sobre a situação clara de profissionais não vocacionados, desmotivados e pouco competitivos, incapazes de responder satisfatoriamente às demandas profissionais e da sociedade.

É função da universidade oportunizar aos acadêmicos a vivência interdisciplinar, estimular o aprendizado interdisciplinar, tanto para aqueles que possuem um perfil aberto para esta prática quanto para aqueles acadêmicos que não possuem.

De acordo com Maia (2013), a interdisciplinaridade depende de uma mudança de atitude em relação ao conhecimento e a troca de uma concepção fragmentada por uma concepção de unidade nas pessoas e em seus fazeres. Essas trocas entre diferentes saberes geram uma nova configuração interna, que, se ouvida e entendida, cria a possibilidade de atitudes interdisciplinares. Isso quer dizer que a atitude interdisciplinar não se dá porque duas ou mais profissões vão habitar o mesmo espaço, mas porque se produz um ambiente no qual os profissionais interagem, se comunicam, trocam e unem informações e conhecimentos.

Quanto ao tema I, sobre pós-graduação, um padrão de resposta foi encontrado: "A interdisciplinaridade é trabalhada na residência multiprofissional".

A residência multiprofissional busca promover a transformação dos serviços de saúde onde estiver inserida instigando a crítica sobre a prática interdisciplinar e as possibilidades e limites de transformação da realidade. Neste caso, a interdisciplinaridade é uma característica intrínseca, conferindo caráter inovador aos programas de residência multiprofissional em saúde, demonstrado principalmente por meio da inclusão das 14 categorias profissionais da saúde. Esse modo de operar a formação 'intercategorias' visa à formação coletiva inserida no mesmo 'campo' de trabalho, sem deixar de priorizar e respeitar os 'núcleos' específicos de saberes de cada profissão (Maia, 2013). 
A formação após a graduação complementa as competências do farmacêutico. Isso é enfatizado por Soares e colaboradores (2008), que propõem como estratégias alternativas de formação complementar (paralelamente à graduação ou após esta), como especializações, residências, estágios, disciplinas optativas etc.

No que tange à categoria 3, sobre a interdisciplinaridade na atuação do farmacêutico no SUS, três temas podem ser destacados. O tema J, referente ao fortalecimento da categoria farmacêutica, trouxe como resposta que “O farmacêutico precisa se fortalecer como categoria por meio de ações políticas, sociais e educacionais, ter voz ativa, aparecer na equipe, junto com outros profissionais".

O farmacêutico no SUS ainda está conquistando seu espaço, já que, apesar de o SUS garantir o acesso aos medicamentos com políticas (PNM e PNAF), não há obrigatoriedade da presença deste profissional no SUS até o momento. Daí a necessidade do fortalecimento da categoria, a fim de conquistar seu espaço no sistema público de saúde e garantir aumento no número de vagas de trabalho.

Além disso, o farmacêutico precisa ser mais atuante na equipe de saúde, mostrando sua competência relacionada ao cuidado ao paciente em uso de terapia farmacológica. A Atenção Farmacêutica é uma das atribuições do profissional que pode auxiliar na promoção do uso racional de medicamentos.

Sobre o tema K, que trata do trabalho em equipe multiprofissional, uma resposta foi evidenciada: "A interdisciplinaridade auxilia o farmacêutico a trabalhar de forma multidisciplinar, em equipe multiprofissional, junto com outros profissionais".

Neste ponto é importante retomarmos os conceitos de multidisciplinaridade, pluridisciplinaridade e interdisciplinaridade. O termo multidisciplinar se refere à junção de disciplinas ou áreas, sem que os profissionais implicados estabeleçam entre si efetivas relações no campo técnico ou científico (Almeida-Filho, 2005).

Já na pluridisciplinaridade os profissionais até estabelecem conexões entre si, há cooperação, porém de forma não coordenada (Almeida-Filho, 2005). Ocorre quando, por exemplo, um paciente procura atendimento psiquiátrico e, após receber orientação e prescrição psicofarmacológica, é encaminhado, pelo próprio psiquiatra, a um psicólogo para um trabalho de psicoterapia. Os profissionais cooperam, mas não se articulam necessariamente de maneira coordenada. Nesse caso, a cooperação não é automática, mas cumpre a finalidade de estabelecer contatos entre os profissionais e suas áreas de conhecimento (Tribarry, 2003).

$\mathrm{Na}$ interdisciplinaridade, exemplificando pelo trabalho em equipe de saúde, as ações seriam planejadas em função das necessidades do grupo 
populacional a ser atendido e não se limitaria às definições apriorísticas de papeis de cada profissional (Garcia et al, 2007).

Entendido desta forma, o termo interdisciplinaridade pressupõe um trabalho coordenado e com objetivo comum, partilhado por vários ramos do saber, de forma integrada e convergente, o que nos reporta imediatamente ao conceito de trabalho em equipe multidisciplinar, base da atuação na Estratégia Saúde da Família. No entanto, a prática nos leva a uma realidade totalmente distinta, em que o trabalho em equipe se aproxima mais do que podemos rotular como pluridisciplinar, já que os conhecimentos profissionais dos componentes das equipes não se integram, reproduzindo o que foi aprendido nos bancos universitários. Geralmente há uma dificuldade de interação entre o médico, o enfermeiro, o odontólogo e o pessoal de nível técnico, já que cada um teve uma formação segundo os princípios éticos e corporativos de cada profissão, desconhecendo os potenciais que existem em cada componente da equipe. Esta falta de integração e comunicação entre os profissionais tem, certamente, a sua origem na graduação, pois cada profissional se forma sem interagir com outros profissionais da saúde, sem um espaço comum de atuação que permita a troca de conhecimentos e possibilite a ação coordenada para atingir um objetivo comum (Santos e Cutolo, 2005).

Quanto ao tema L, que trata da atuação do farmacêutico no sistema público e privado, uma resposta foi marcada: “O sistema privado emprega mais farmacêuticos do que o SUS".

Soares e colaboradores (2008) discutem a questão da preparação dos farmacêuticos para o mercado de trabalho. Os autores salientam o fato de as diretrizes curriculares, assim como do próprio movimento da reforma sanitária, definirem o foco da formação dos profissionais de saúde voltado para o atendimento das necessidades sociais, mais especificamente para a consolidação do SUS, o que não necessariamente significa formação para as demandas do mercado de trabalho. A maioria dos egressos dos cursos de graduação em Farmácia tem no setor privado (ramo de farmácias comerciais e drogarias) a principal fonte de emprego.

Neste ponto, o papel da universidade é complexo e precisa ser repensado. De acordo com Soares e colaboradores (2008), alguns formadores defendem o fato de que a universidade deveria formar bons vendedores de medicamentos, com habilidades de marketing e gerência comercial. No entanto, mesmo não negando a necessidade de preparar o farmacêutico para a realidade do mercado, a universidade deve assumir o seu papel na mudança da sociedade, direcionando a formação de profissionais capazes de construir novas formas de organização social, mais justas e éticas. 


\section{Considerações finais}

Apesar de a interdisciplinaridade permear o perfil de habilidades específicas do profissional farmacêutico, conforme citam as DCN (Brasil, 2002), os resultados revelaram uma série de dificuldades, contradições e conflitos sentidos pelos coordenadores de cursos de Farmácia sobre como desenvolver a prática interdisciplinar nas atividades acadêmicas.

A partir dos depoimentos, verificou-se que é preciso, antes de tudo, compreender melhor o que é a interdisciplinaridade e como é que ela se relaciona no currículo e na formação do farmacêutico, assim como em quais momentos deve ser estimulada.

Além disso, as falas demonstraram claramente uma confusão do que se entende por profissional generalista e especialista, assim como a impossibilidade de se formar um farmacêutico competente em todas as áreas de atuação. Ficou clara a falsa relação existente de que a interdisciplinaridade é intrínseca à formação generalista e se afasta da formação especialista. No entanto, a interdisciplinaridade pode ser estimulada em ambos os casos, uma vez que ela auxilia o especialista a desenvolver uma visão menos fragmentada.

A formação docente foi apontada como um dos problemas que impedem uma prática interdisciplinar efetiva no currículo de Farmácia, já que a maioria dos professores foi formada numa visão cartesiana e possivelmente nunca vivenciou a prática interdisciplinar. Um dos motivos apontados nos depoimentos foi a falta de formação na área pedagógica. Neste quesito, uma das soluções é a busca de equipes qualificadas para prestar assessoria na construção desse tipo de currículo. Muitos currículos integrados de cursos de Medicina e Enfermagem, por exemplo, foram implementados a partir do auxílio de pedagogos e de profissionais de saúde com expertise na implantação de currículos inovadores.

Os resultados revelaram, ainda, outro motivo que gera dificuldades em implementar um currículo inovador e interdisciplinar em cursos de graduação em Farmácia, a disputa de poder entre as áreas, mais precisamente entre os eixos de fármaco-medicamentos, análises clínicas e a área de tecnologia de alimentos. Num currículo de quatro mil horas, não é possível formar um profissional competente em todos os níveis de complexidade para os três eixos de atuação. No entanto, priorizar a formação em uma ou outra área poderia significar, aparentemente, a perda de poder da área menos favorecida. Talvez este seja um dos principais motivos pela lacuna em iniciativas de mudanças no ensino farmacêutico.

Portanto, dentro de uma formação com tantas subáreas, é necessário estabelecer prioridades e níveis de complexidade das competências para os farmacêuticos que se quer formar. Certamente, assim como na formação médica e de outras profissões, não se pode formar um profissional com um 
mesmo nível de competência em todas as áreas de atuação. Por isso, o estabelecimento do perfil profissiográfico do farmacêutico é fundamental. Por meio deste perfil se definem quais habilidades os egressos dos cursos de Farmácia devem dominar, com base em objetivos educacionais que se quer desenvolver nos acadêmicos, os quais precisam ser traçados nos três domínios: cognitivo, afetivo e psicomotor.

Os resultados evidenciaram, ainda, que não houve consenso nos depoimentos se as DCN pioraram ou melhoraram a formação do farmacêutico. Isto pode ser considerado um problema grave, já que, depois de mais de uma década da publicação das diretrizes curriculares, ainda não se avançou na busca de melhorias na formação do profissional.

O SUS também foi alvo de críticas nos depoimentos. O profissional farmacêutico foi visto de forma desvalorizada no setor público, tanto no trabalho em equipe multiprofissional quanto na sua sustentabilidade no sistema. Outro ponto de destaque que emergiu nos depoimentos foi a questão do mercado de trabalho do setor privado, que absorve boa parte dos egressos dos cursos de graduação. Daí o questionamento se formar profissionais para o SUS atende a demanda da sociedade.

Diante do exposto, verificou-se que o debate sobre a formação do farmacêutico precisa ser explorado tanto na academia quanto no mercado de trabalho, a fim de buscar consensos sobre os caminhos a serem percorridos para que o farmacêutico possa ser aquele profissional necessário para atender as necessidades de saúde da população.

\section{Agradecimentos}

Os autores agradecem aos coordenadores de curso de Farmácia que aceitaram participar da pesquisa. Também agradecem à Coordenação de Aperfeiçoamento de Pessoal e Nível Superior (Capes) pelo fomento da pesquisa da tese de doutorado $A$ interdisciplinaridade na formação farmacêutica: uma abordagem à luz da Fenomenologia, de autoria de Iane Franceschet de Sousa, cujos resultados preliminares estão contidos neste artigo. 


\section{Colaboradores}

\section{Ambos os autores foram responsáveis pela elaboração e revisão do manus-} crito. Os autores declaram não haver conflitos de interesse.

Resumen La interdisciplinaridad se presenta como un desafío y una necesidad del sector de salud, teniendo en vista la reorientación del modelo asistencial. Este estudio buscó revelar la comprensión de coordinadores de cursos de graduación en Farmacia de la región Centro-Oeste de Brasil sobre la interdisciplinaridad en la formación del farmacéutico. Se utilizó el abordaje cualitativo, en la hipótesis metodológica de la fenomenología, según la modalidad del fenómeno situado. Se recogieron 16 testimonios entre junio de 2011 y abril de 2012 y se sometieron a la descripción, reducción e interpretación fenomenológica, a fin de llegar al conocimiento del fenómeno estudiado. La construcción de los resultados se realizó en base a los análisis ideográfico e nomotético de los testimonios, de los cuales surgieron 12 temas, agrupados en tres categorías principales: interdisciplinaridad en el currículo, interdisciplinaridad en la formación del farmacéutico e interdisciplinaridad en la actuación del farmacéutico en el sistema de salud. Algunos resultados revelados refieren a la necesidad de comprender mejor cómo la interdisciplinaridad dialoga con el currículo de Farmacia, y a la superación de obstáculos técnicos y políticos que impiden la práctica interdisciplinaria efectiva en la formación de los farmacéuticos, entre ellos la falta de capacitación docente y las disputas de poder entre áreas.

Palabras clave educación en farmacia; currículo; interdisciplinaridad; directrices curriculares nacionales.

\section{Notas}

1 Universidade Estadual de Mato Grosso do Sul, Unidade Universitária de Campo Grande, Curso de Medicina, Campo Grande, Mato Grosso do Sul, Brasil.

<ianefran@gmail.com>

Correspondência: Rua José Gomes Domingues, n. 457, apto. 1.502, Bairro Santa Fé, CEP 79021-230, Campo Grande, Mato Grosso do Sul, Brasil.

2 Universidade Federal de Mato Grosso do Sul, Centro de Ciências Biológicas e da Saúde, Programa de Pós-Graduação em Saúde e Desenvolvimento na Região Centro-Oeste, Campo Grande, Mato Grosso do Sul, Brasil.

$<$ phaidamus43@gmail.com> 


\section{Referências}

ALMEIDA-FILHO, Naomar. Transdisciplinaridade e o paradigma pós-disciplinar na saúde. Saúde e Sociedade, São Paulo, v. 14, n. 3, p. 30-50, 2005.

ANDERSON, Claire et al. The WHO UNESCO FIP Pharmacy Education Taskforce: Enabling Concerted and Collective Global Action. American Journal of Pharmaceutical Education, Alexandria, v. 72, n. 6, 2008.

ARAÚJO, Fernanda Q.; PRADO, Eliane M. Análise das Diretrizes Curriculares Nacionais do curso de graduação em Farmácia. Revista Contemporânea de Educação, Rio de Janeiro, v. 5, p. 96-108, 2008.

ARAÚJO, Maria E. Palavras e silêncios na educação superior em odontologia. Ciência \& Saúde Coletiva, Rio de Janeiro, v. 11, n. 1, p. 179-182, 2006.

BRAID, Liana M. C.; MACHADO, Maria F. A. S.; ARANHA, Ágatha C. Estado da arte das pesquisas sobre currículo em cursos de formação de profissionais da área da saúde: um levantamento a partir de artigos publicados entre 2005 e 2011. Interface: Comunicação, Saúde e Educação, Botucatu, v. 16, n. 42, p. 679-692, 2012.

BRASIL. Conselho Nacional de Educação. Resolução CNE/CES n. 2, 19 de fevereiro de 2002. Institui Diretrizes Curriculares Nacionais do Curso de Graduação em Farmácia. Diário Oficial da República Federativa do Brasil, Brasília, DF, 19 fev. 2002.

BRASIL. Ministério da Educação. Brasília, DF, 23 dez. 1996. Estabelece as diretrizes e bases da educação nacional. Diário Oficial da República Federativa do Brasil, Brasília, DF, 23 dez. 1996.

BRASIL. Ministério da Educação. Parecer CNE n. 1133/01. Diretrizes Curriculares Nacionais dos Cursos de Graduação em Enfermagem, Medicina e Nutrição. Diário Oficial da República Federativa do Brasil, Brasília, DF, 3 out. 2001a.
BRASIL. Ministério da Educação. Parecer CNE n. 1300/01. Diretrizes Curriculares Nacionais dos Cursos de Graduação em Farmácia e Odontologia. Diário Oficial da República Federativa do Brasil, Brasília, DF, 7 dez. 2001 b.

BRASIL. Ministério da Educação. Parecer CNE n. 776/97. Orienta para as diretrizes curriculares dos cursos de graduação. Diário Oficial da República Federativa do Brasil, Brasília, DF, 3 dez. 1997.

BRASIL. Politica Nacional de Extensão Universitária. Fórum de Pró-Reitores de Extensão das Instituições de Educação Superior Públicas Brasileiras. Manaus: Rede Nacional de Extensão, 2012.

BRASIL. Ministério da Educação. Instituições de ensino superior e cursos cadastrados. Consulta avançada. 2010. Disponível em: <http://emec.mec.gov.br/>. Acesso em: 3 out. 2010 .

CARPES, Adriana D.; MAGNI, Joceléia A. Búsqueda de un nuevo perfil para el farmacéutico: la readaptación de los currículos en Cursos de Farmacia. Formación Universitaria, La Serena, v. 2, n. 3, p. 3-10, 2009.

CECY, Carlos. Diretrizes curriculares: dez anos. Pharmacia brasileira, Brasília, ano XII, n. 80, p. 53-56, 2011.

DELORS, Jacques (org.). Educação: um tesouro a descobrir. Relatório para a Unesco da Comissão Internacional sobre Educação para o século XXI. São Paulo: Cortez, 1996.

FAZENDA, Ivani C. A. Integração e interdisciplinaridade no ensino brasileiro. São Paulo: Edições Loyola, 1993.

FAZENDA, Ivani C. A. Interdisciplinaridade: história, teoria e pesquisa. 16. ed. São Paulo: Papirus, 2009.

FORGHIERI, Yolanda C. Psicologia fenomenológica. São Paulo: Pioneira, 1993. 
FURTADO, Vivian. Análise do processo de implementação das Diretrizes Curriculares Nacionais do Curso de Graduação em Farmácia no Estado do Rio de Janeiro: um estudo exploratório. Dissertação (Mestrado em Medicina Social) Instituto de Medicina Social, Universidade do Estado do Rio de Janeiro, Rio de Janeiro, 2008.

GARCIA, Maria A. A. et al. A interdisciplinaridade necessária à educação médica. Revista Brasileira de Educação Médica, Rio de Janeiro, v. 31, n. 2, p. 147-155, 2007.

GATTÁs, Maria L. B.; FUREGATO, Antonia R. F. Interdisciplinaridade: uma contextualização. Acta Paulista de Enfermagem, São Paulo, v. 19, n. 3, p. 323-327, 2006.

GRAY, Geneviève. Promoting collaboration between health science disciplines at the University of Alberta, Canada. Texto \& Contexto Enfermagem, Florianópolis, v. 14, n. 3, p. 358-363, 2005.

LEITE, Silvana N. et al. A identidade do farmacêutico em foco: resultados do fórum de educação farmacêutica do CRF/SC. Comunicador Farmacêutico, Florianópolis, v. 33, n. 9, p. 14-17, 2006.

MAIA, Danielle B. et al. Atuação interdisciplinar na Atenção Básica de Saúde: a inserção da Residência Multiprofissional. Saúde \& Transformação Social, Florianópolis, v. 4, n. 1, p. 103-110, 2013.

MARTINS, Joel. Um enfoque fenomenológico do currículo: educação como poíesis. São Paulo: Cortez; 1992.

MARTINS, Joel; BICUDO, Maria A. V. A pesquisa qualitativa em psicologia: fundamentos e recursos básicos. São Paulo: Moraes, EDUC, 1994.

PAGLIOSA, Fernando L.; DA ROS, Marco A. Relatório Flexner: para o bem e para o mal. Revista Brasileira de Educação Médica, Rio de Janeiro, v. 32, n. 4, p. 492-499, 2008.

RIBEIRO JÚNIOR, João. Fenomenologia. São Paulo: Pancast, 1991.
ROSSONI, Eloá; LAMPERT, Jadete. Formação de profissionais para o Sistema Único de Saúde e as diretrizes curriculares. Boletim da Saúde, Porto Alegre, v. 18, n. 1, p. 87-98, 2004.

SADALA, Maria L. A. Estar com o paciente: a possibilidade de uma maneira autêntica de cuidar. Tese (Doutorado em Enfermagem) Escola de Enfermagem, Universidade de São Paulo, São Paulo, 1995.

SADALA, Maria L. A.; MARQUES, Sílvio A. Vinte anos de assistência a pessoas vivendo com HIV/Aids no Brasil: a perspectiva de profissionais da saúde. Cadernos de Saúde Pública, Rio de Janeiro, v. 22, n. 11, p. 2.369-2.378, 2006.

SANTOS, Marco A. M.; CUTOLO, Luiz R. A. A interdisciplinaridade e o trabalho em equipe no Programa de Saúde da Família. Arquivos Catarinenses de Medicina, Florianópolis, v. 33, n. 3, p. 31-40, 2004.

SAUPE, Rosita; BUDÓ, Maria L. D. Pedagogia interdisciplinar: 'educare' (educação e cuidado) como objeto fronteiriço em saúde. Texto \& Contexto Enfermagem, Florianópolis, v. 15, n. 2, p. 326-333, 2006.

SAUPE, Rosita; CUTOLO, Luiz R. A.; WENDHAUSEN, Águeda L. P. et al. Competência dos profissionais da saúde para o trabalho interdisciplinar. Interface: Comunicação, Saúde e Educação, Botucatu, v. 9, n. 18, p. 521-536, 2005.

SILVA, Rinaldo H. A.; MIGUEL, Soraida S.; TEIXEIRA, Luciana S. Problematização como método ativo de ensino-aprendizagem: estudantes de farmácia em cenários de prática. Trabalho Educação e Saúde, Rio de Janeiro, v. 9, n. 1, p. 77-93, 2011.

SILVA, Wellington B. A emergência da atenção farmacêutica: um olhar epistemológico e contribuições para o seu ensino. Tese (Doutorado em Educação Científica e Tecnológica) - Centro de Ciências da Educação, Universidade Federal de Santa Catarina, Florianópolis, 2009. 
SOARES, Luciano et al. Educação farmacêutica e identidade profissional. In: CORDEIRO, Benedito C.; LEITE, Silvana S. N. (orgs.). $O$ farmacêutico na atenção à saúde. 2 ed. Itajaí: Univali, 2008. p. 263-286.

TRIBARRY, Isac N. Aproximações sobre a transdisciplinaridade: algumas linhas históricas, fundamentos e princípios aplicados ao trabalho de equipe. Reflexão e Crítica, Porto Alegre, v. 16, n. 3, p. 483-490, 2003.

Recebido em 25/03/2013

Aprovado em 14/09/2014 